\title{
Leer estribillos
}

\section{Tamara Kamenszain}

Llegué a los libros de Héctor Viel Temperley gracias a Fogwill. Lector intenso y apasionado si los hubo, te obligaba a leer lo que consideraba que te serviría para escribir. Y casi siempre acertaba. Viel por ese entonces (hacia 1985) era un perfecto desconocido, pero no en el sentido del escritor de culto que encarna un secreto a voces para un grupo de personas. Literalmente casi nadie, salvo Fogwill, lo había oído nombrar en el ambiente. Sin embargo, para ese entonces Viel ya tenía publicados nueve libros de poemas. Claro que se trataba de publicaciones heterodoxas, casi todas en editoriales prefabricadas ad hoc. Cuando Fogwill me lo nombró por primera vez, se apareció en mi casa con aquella edición de Crawl impresa en el taller de los salesianos en 1982 y cuya mítica tapa -el retrato de un marinero enmarcado en una corona de espinasreprodujo años después Ediciones del Dock. En la única entrevista que existe, pocos meses antes de morirse, cuando ya estaba internado en el Hospital Británico, Viel le explica al entonces joven Sergio Bizzio que la disposición de los poemas en la página toma la forma de un hombre nadando crawl. Cuando el estribillo "Vengo de comulgar y estoy en éxtasis", que se repite ocho obstinadas veces a lo largo del libro, ya se había transformado para mí en una alarma auditiva que me hacía segregar adrenalina literaria, le pedí a Bizzio que me facilitara fotocopias de esos otros libros de Viel que él, que los había conseguido en función de la entrevista, mostraba como un trofeo. Así fue como me hice de Cartas de marear, de 1976 -que traía, como bonus track, una contratapa de Enrique Molina- y Legión extranjera, de 1978.

Leyendo ese paquete de páginas que después anillé y conservo hasta hoy, entendí que en esa zona que queda palpitando entre que me cuenten algo y que de golpe me lo dejen de contar, se aloja la poesía. Se trata de una suspensión placentera que me atrapa con su ritmo. Y cuando hace alrededor de 25 años me topé por primera vez, en Legión Extranjera, con "Bajo las estrellas del invierno", supe que iba a tener que convocar ese poema hasta el cansancio para poder "ver hacer", una y mil veces, el rompecabezas cuyos fragmentos se dirigen, como coreografiados, hacia un imán narrativo.

Algo parecido me pasa con "Alta Marea" de Enrique Molina que, partiendo del emblemático verso "cuando un hombre y una mujer que se han amado se separan", despliega una historia de amor que se pierde y se retoma permanentemente a lo largo del poema. Cada vez que se retoma, opera como un premio para el lector de poesía. Siempre dispuesto a dejarse perder sabiendo que ese esfuerzo le será compensado con una sorpresa narrativa, ese lector se transforma en un sabueso que busca rastros 
donde otros no ven nada. Molina lo sabe y cuando el poema, mareado entre metáforas surrealistas, amenaza con írsele de las manos, lo hace bajar a tierra con versos como estos: "dos o tres libros y una camisa en una maleta / llueve y el tren desliza un espejo frenético por los rieles de la tormenta / el hotel da al mar". El paquete de objetos -libros, camisas, maleta, un tren, un hotel- se pone en movimiento solo, mientras una sombra, como salida de un cuadro impresionista, lo atraviesa huyendo por la estela de luz que esos objetos despliegan. A partir de ahí, para leer alcanza con volverse voyeur. Hasta las paredes altas del hotel nos abren sus ventanas dejándonos espiar, a nosotros que andábamos a los saltos entre cortes de verso, los entretelones de una experiencia íntima: "cada noche cuando te desvestías / la sombra de tu cuerpo desnudo crecía sobre los muros / hasta el techo".

En la adolescencia, cuando recalé por primera vez en estos versos, los libros, las camisas, la maleta, el hotel, el tren también estaban ahí como para decirme que la poesía se hace con las palabras que todos los días encuentran su sentido en lo cotidiano. Y que lo que se quiere expresar no es otra cosa que el presente de un acontecimiento subjetivo, ese al que alude Molina en la contratapa a Carta de marear de Viel Temperley: "La poesía relata sucesos pero lo hace desde la raíz, en el foco de una experiencia". No sé si conceptos como este eran claros para mí en ese entonces, seguramente no. Pero lo que sí es seguro es que yo buscaba en la poesía lo que busca cualquier joven: reeditar las primeras experiencias importantes, sobre todo las amorosas y, más específicamente, esas en las que se producen las rupturas. Ahí, cuando vienen los primeros desencantos de la vida, la poesía, género medio melancólico que busca siempre decir algo sobre el objeto perdido, se hace presente en las lecturas juveniles. Cuando mi hijo Mauro tuvo su primer desengaño amoroso estaba desconsolado y a mí no se me ocurrió mejor idea que fabricarle una pequeña antología de poemas llorones para reconfortarlo. Ahí estaban, entre otros, "Alta Marea" por supuesto, pero también el poema 20 de Pablo Neruda que desde su comienzo mismo, "Puedo escribir los versos más tristes esta noche", impulsa a los jóvenes a ponerse a escribir a partir de una desilusión amorosa. También estaba el "Poema para gritar entre las ruinas", de Louis Aragon, en una magnífica traducción de Victoria Rabin, cuyo estribillo "Los dos escupamos los dos / sobre aquello que hemos amado" repetíamos siempre con mi grupo de amigos como si escupir fuera un hecho estético.

Creo que mi hijo se consoló un poco con los poemas o, como él mismo confiesa, por lo menos entró por primera vez en relación con la poesía (que no es poca cosa). Así fue como, cuando murió Nicolás Casullo, el marido por casi 40 años de Ana Amado, mi mejor amiga, reedité lo que había hecho con Mauro. Ella estaba inconsolable y le mandé el poema "En la brisa, un momento", que Olga Orozco escribió después de la muerte de su propio marido, Valerio Peluffo. Sabía que a Ana le encantaba Orozco y supuse, ya que a mí me suele pasar eso, que leer un poema donde otro puede expresar lo que nosotros hubiéramos querido decir, sirve de consuelo. La reacción de mi amiga fue inesperada: "vos siempre con tu onda judeo-masoquista". Después me explicó que había llorado mucho leyendo el poema y que eso la había empeorado. En esa respuesta de la que fuera casi una hermana durante los últimos 35 años, estaba encerrada una complicidad que marcó nuestra amistad: siempre, como un modo de diferenciarnos para unirnos, apelábamos a la humorada de que yo era judía y ella palestina. Dos territorios en lucha que se enfrentaban al mismo tiempo que con eso reforzaban la cercanía. Meses después, Ana empezó a comentarme el poema. Le había encantado cómo Orozco invocaba los objetos de su marido: "Y qué será tu almohada / y qué serán tus sillas / y qué será tu ropa, y hasta mi lecho a solas, si me animo". Pero, sobre todo, lo que la volvía loca era una alusión a la cuchara: "aléjate, memoria de pared, memoria de cuchara, memoria de zapato". 
Cuando en 2017 Ana murió, yo estaba tan desconsolada que intenté ver si escribiendo un poema alusivo me podía llegar a calmar. Como no me salía, me puse a googlear los poemas para amigos muertos que aparecían en la web pero no había caso, no me inspiraba ninguno. Creo que ella tenía razón cuando me dijo lo del masoquismo judío: hay que haber atravesado primero el duelo para poder después decir algo sobre la persona que nos deja, sin correr el riesgo de reabrir la herida. Ahora creo que ese poema sobre Ana ya estaba escrito. César Vallejo, cuando alude a Pedro Rojas, un miliciano muerto en la guerra civil española cuyo cadáver fue encontrado a la vera del camino con una cuchara en el bolsillo, escribe esto: "Registrándole, muerto, sorprendiéronle / en su cuerpo un gran cuerpo / para el alma del mundo / y en la chaqueta una cuchara muerta. / Pedro también solía comer / entre las criaturas de su carne, asear, pintar / la mesa y vivir dulcemente en representación de todo el mundo. / Y esta cuchara anduvo en su chaqueta, despierto o bien cuando dormía, siempre / cuchara muerta viva, ella y sus símbolos." Y termina Vallejo el largo poema a Pedro Rojas con aquel emblemático verso en oxímoron que puso patas para arriba la poesía latinoamericana anterior a él: "su cadáver estaba lleno de mundo".

Lo que me consuela ahora mismo, que evoco a Ana Amado y transcribo este poema de Vallejo para ella y por ella, es la certeza de que la poesía puede hacer algo con las rupturas y las muertes. No puede evitarlas, no puede resucitar a los muertos, no puede rehacer las parejas rotas pero, enfocándose en lo más nimio -cuchara, mesa, chaqueta, incluso cadáver- puede quizá calmar la desesperación ante lo irreparable y reponer el valor de uso del objeto perdido. Pero lo paradojal es que al mismo tiempo que logra bajar ese objeto a tierra, le aporta universalidad. En uno de los estribillos del poema "Bajo las estrellas del invierno", Viel Temperley anuncia así ese salto hacia lo universal: "hablo de todas las horas y de todos los días / y de todas las estaciones y de todos los años". Este poema viene a continuar la serie que se titula "Poemas de la bolsa de dormir" y, si sumamos ese título a las fotos de Viel que trascendieron -un tipo fornido, de torso desnudo, hachando leña-resulta en un combo que nada tiene que ver con la imagen que por entonces teníamos de nuestros poetas de exportación. Desde Lugones hasta Juarroz pasando por el mismísimo Girri, se nos conocía afuera por una poesía blanca, abstracta, cuasi metafísica, nada vital (Juarroz, hacia la década del 8o, era el poeta más traducido). Viel, por su parte, un absoluto outsider, instala para la misma época su máquina narrativo-poética a cielo abierto, en medio de un campamento a la vera del mar, donde al hablante le pasa de todo: una perra le busca el pene a la noche cada vez que sale a orinar desnudo; salva a una mujer que le pide auxilio desde el mar y ayuda a orinar a un enfermo -"su pene entre mis dedos"mientras marchan juntos hacia un hospital cruzando playas de estacionamiento. Al final, el poeta se describe a sí mismo vagando con una pistola en el puño "sin tener dónde afeitarme". Así, entre los asuntos propios y los de todos, se va armando una antinovela narrada en presente y con final abierto. A ningún lector de poesía se le ocurriría preguntar qué hizo después el poeta con esa pistola, porque el estribillo que habla de todos los días y de todas las horas y de todas las estaciones y todos los años le pone freno a cualquier ficción. No por nada cuando se estaba muriendo, internado en el Hospital Británico, Viel anotó esto tan íntimo y secreto pero a la vez tan universal: "voy hacia lo que menos conocí en mi vida / voy hacia mi cuerpo".

Creo que lo que a mí me atrajo desde chica de leer poesía fue justamente ese murmullo que segregan las historias cuando se suspenden y se retoman desde un ritmo que se escucha cerca, íntimamente. En esa voz que devuelve la historia a la lectura al mismo tiempo que la abandona, lo que se escucha es siempre el estribillo. Casi diría que leer para mí es leer estribillos. Cuando en el aula del Liceo de Señoritas $\mathrm{N}^{\circ} 1$, la profesora de lengua nos leyó el "Nocturno III" de José Asunción Silva, me topé por primera vez con esa voz. Cuando llegó al estribillo que tartamudea "y eran una / y eran una / y eran una sola sombra larga", me lo anoté con lápiz en la tapa interna 
de mi carpeta. Creo que fue el primer poema ajeno que intenté escribir yo. Años después me enteré de que algunos biógrafos refieren a un supuesto amor prohibido entre Asunción Silva y su hermana, intentando darle un final de novela a lo que en esa agónica repetición es puro secreto entre lector y escritor.

No debe ser casual que Néstor Sánchez, un escritor que se la pasó jaqueando los cierres narrativos -baste recordar los "cuatro finales posibles" de Siberia Blues- haya sido el que, a mis 20 años, me enseñara a leer poesía pescando el ritmo íntimo de alguna historia siempre fragmentaria. La muerte de Lou, la mujer de Michaux quemada en un accidente cuando en el poema "Nosotros dos aún" la voz repite "Lou / Lou / Lou en el retrovisor de un breve instante / Lou ¿no me ves?", o la locura de Naomí, la madre de Allen Ginsberg señalada repetidamente en Kaddish, eran algunos de los poemas que leíamos en voz alta con el grupo de jóvenes amigos que frecuentábamos a Sánchez. Él también nos impulsaba a hacer traducciones caseras a pesar de nuestra común condición de monolingües. Quizás fue justamente él quien impulsó a Vicky Rabin, por entonces su mujer, a traducir el poema de Aragon. Por mi parte, al llegar a casa de mis padres a altas horas de la noche, me encerraba en mi cuarto e intentaba traducir, o mejor adivinar, partes de Kaddish desde mi inglés inexistente. "Oh madre / adiós / con tu largo zapato negro / adiós / con el partido comunista y la media rota [...] adiós / con tu miedo a Hitler / con tu mentón de Trotsky y de Guerra Civil Española".

Como las camisas, los libros o la maleta del amante fugitivo de Molina, el poema de Ginsberg aludía para mí a objetos tan simples y cotidianos como los que se estudian en el primer nivel de inglés. En Kaddish, Ginsberg se da el lujo de ir estirando ese idioma coloquial para hacernos participar, a nombre de Naomi, de su propia historia. Desde que él tiene 12 años y la lleva a internar por primera vez a un neuropsiquiátrico hasta que, veinte años después, ella muere y le deja al hijo una carta póstuma (“Tengo la llave. Casate, Allen, no tomes drogas, la llave está en la reja, en la luz del sol de la ventana"). El relato no se detiene ante nada porque no tiene la obligación de cerrar ningún cuento. "Cantos, no cuentos", pedía Néstor Perlongher, nuestro rey del estribillo, y en su emblemático poema-libro Cadáveres, el estribillo está cantado: "Hay cadáveres" se repite 53 veces. Cada una de esas veces, cuando la lectura del texto me va adormeciendo dentro de la espiral metafórica perlongheriana, suena un despertador que me recuerda lo que hay y me libera de lo que sobra.

Me parece, entonces, que cuando leo poesía lo hago siempre esperando que lleguen esos golpes de realidad para que me liberen de lo que Gombrowicz, en su ensayo Contra los poetas, llamó "exceso": "exceso de palabras poéticas, exceso de metáforas, exceso de sublimación, exceso, por fin, de la condensación, de la depuración de todo elemento antipoético". Lo que sobra, entonces, llama por la boca del estribillo a lo que falta: cada vez que la voz del despertador me dice y me repite lo que hay, sé que alguien practicó un paso de prosa haciendo trastabillar la fijeza de los propósitos poéticos. Ahora bien, arruinar la poesía a golpes de estribillo, salirse alegremente del verso, no es tarea para cualquiera. Llamo "vates" a los que instalan sus dominios en un terreno inamovible. Desde ese cuartel no solo se creen a sí mismos poetas sino que además se ocupan de cuidar la quintita con ahínco. El enojo de Gombrowicz define así el producto que resulta de semejante creencia: "por cada diez versos habrá al menos uno dedicado a la adoración del poder de la Palabra Poética o de la glorificación de la vocación del Poeta". Es desde esa ostentación de poderío desde donde los vates le cortan los pies al poema. (Aquí, si yo escribiera en lenguaje inclusivo -algo a lo que todavía no me animo ni sé bien cómo hacer- dejaría vate en su acepción masculina ya que esta condición me remite, sin lugar a dudas, a un rasgo patriarcal).

Lejos de creerse vate, Néstor Perlongher tuvo que hacer malabares para recuperar 53 veces su verdad cantada. Al final, cuando el estribillo "Hay cadáveres" se 
le iba escurriendo entre los dedos, ensayó con preguntas: “¿Hay cadáveres?”, “¿Se entiende?", “¿Estaba claro?", “¿No era un poco de más para la época?”. No es casual que Néstor haya escrito Cadáveres en un viaje en ómnibus entre Buenos Aires y São Paulo, camino a un exilio forzado. En una especie de frenético Ensaio de voo terrestre, seguramente él también se propuso, como Paloma Vidal, abarcar una cantidad de caracteres en el camino. Me lo imagino leyéndose y releyéndose asustado de no poder soltar un mismo estribillo obsesivo que se le iba imponiendo a lo largo del viaje. ¿Qué sabía él en ese entonces, anti-vate total huyendo de la homofobia de la dictadura militar, que el verso "Hay cadáveres" iba a quedar tatuado -como contraseña de usos múltiples- entre los lectores de poesía por varias generaciones?

Años después Néstor grabó un audio leyendo Cadáveres. Escuchándolo me queda claro que no se aprovechó de ninguna imagen, de ninguna palabra, de ningún hallazgo lingüístico y mucho menos de la recurrencia fónica del estribillo para acentuar nada. Con esa tonalidad que voy a llamar marica porque suena indiferente a la falsa potencia de la voz, casi frívola, propia de la más auténtica desmitificación de la masculinidad, pareció querer decirnos que no esperemos de la poesía consecuencias épicas ni líricas porque él está llegando a destino y se va a bajar del ómnibus y los 53 estribillos ya se le terminaron. Por eso el último verso dice que "no hay cadáveres". Es el final del trayecto que dio como resultado un libro. Lo que era un poema largo que los estribillos cosían con afirmaciones, queda ahora encuadernado gracias a un ejercicio de negación. Leer estribillos, entonces, supone el placer de anticiparse a dejar de leer. Porque mientras recibimos esas repeticiones, percibimos cómo se van alejando juntas para terminar propinando un último golpe de realidad: el libro. Lezama Lima llamó a este acto de malabarismo poético "fragmentos a su imán". Pero para poder hacer esa pirueta no alcanza con rejuntar una colección de poemas ni tampoco con acopiar una serie que responda a un tema predeterminado. Recalar en libro supone que los fragmentos caigan de maduro como diciendo hasta aquí llegamos. Ahí es cuando aparece el silencio como último regalo que el escritor le hace al lector. Se trata de un sonido que se desmiente a sí mismo o, mejor, de un ritmo que, como diría Henri Meschonnic, lo único que ahora deja escuchar es al sujeto.

Cuando Perlongher, internado en São Paulo enfermo de SIDA, insistía con el estribillo "ahora que me estoy muriendo", invocaba al mismo tiempo a Viel: "gemidos del doble que no se ve del hospital (británico)". Para ese entonces Viel ya había muerto pero, como se puede ver, "su cadáver estaba lleno de mundo" porque logró consolar al moribundo que, desde su lejano exilio, lo escuchó y se escuchó en un eco doble de lecturas y escrituras. 
